\title{
Use of choline PET for studying hepatocellular carcinoma
}

\author{
Jean-Noël Talbot $\cdot$ Laure Michaud • \\ Jean-Didier Grange · Olivier Rosmorduc • \\ Sona Balogova
}

Received: 12 September 2013/Accepted: 6 February 2014/Published online: 13 March 2014

(C) Italian Association of Nuclear Medicine and Molecular Imaging 2014

\begin{abstract}
Accurate detection of hepatocellular carcinoma (HCC) foci in the liver and at the whole-body level has a significant impact on patient management. Functional whole-body imaging by PET (fused with CT or MRI) with spatial resolution compatible with the detection of lesions $<2 \mathrm{~cm}$ in size has been proposed to overcome some limitations of morphological imaging. ${ }^{18} \mathrm{~F}$-fluorodeoxyglucose (FDG), the reference PET tracer in oncology, has limitations in the functional imaging of liver tumours. In particular, the detection rate of intra-hepatic, welldifferentiated HCC is low and incompatible with effective staging of affected patients. To overcome this lack of sensitivity, choline PET tracers have been used by several teams: ${ }^{11} \mathrm{C}$-choline or its analogues. ${ }^{18} \mathrm{~F}$-fluorocholine (FCH) and ${ }^{18} \mathrm{~F}$-fluoroethylcholine (FEC). These tracers
\end{abstract}

Color figures online at http://link.springer.com/article/10.1007/ s40336-014-0055-1

J.-N. Talbot · L. Michaud · S. Balogova $(\varangle)$

Department of Nuclear Medicine, Hôpital Tenon,

AP-HP, Paris, France

e-mail: sona.balogova@tnn.aphp.fr

J.-N. Talbot · L. Michaud · J.-D. Grange · O. Rosmorduc Université Pierre et Marie Curie, Paris, France

J.-D. Grange

Department of Gastroenterology, Hôpital Tenon AP-HP, Paris, France

O. Rosmorduc

Department of Hepatology, Hôpital Saint-Antoine,

AP-HP, Paris, France

S. Balogova

Department of Nuclear Medicine, Comenius University, Bratislava, Slovakia showed sensitivity compatible with accurate staging of well-differentiated HCC and also of intermediate or poorly differentiated HCC. Dual-tracer PET using FDG and a lipid tracer has the best performance, since the aggressiveness of lesions within a given patient may vary, with some taking up only one tracer. Such variability of uptake may also be seen between different portions of a single large liver nodule. There is some evidence to suggest that a dualtracer approach can be beneficial in the detection of distant metastases. Dual-tracer PET can also be useful in the selection of patients for liver transplantation or HCC tumour resection, for optimal pre-therapeutic staging, and potentially for prediction of recurrence. In pilot studies, visualisation of HCC tumours with FDG was found to indicate a worse prognosis, whereas visualisation with a lipid tracer was indicative of a better prognosis. Among non-HCC liver malignancies in adults, only cholangiocarcinoma has been reported to take up lipid tracers in small series; FCH uptake has been reported in a child with recurrent hepatoblastoma. With regard to benign liver tumours, adenoma is rarely visible on choline PET, whereas focal nodular hyperplasia (FNH) is visible as a hot focus in the vast majority of cases. When using PET to characterise a liver nodule as HCC, this uptake by FNH may constitute a source of false-positive results. According to one team, FCH could be a good tracer to use in difficult cases for differentiating between FNH and hepatocellular adenoma which can potentially show malignant degeneration. From a logistical point of view, FCH is the easiest of the choline PET tracers: it has a longer half-life (110 min), can be produced industrially, and has been granted a marketing authorisation for this indication. The aim of the article is to provide an overview of PET imaging using the lipid tracer choline and its fluorinated analogues for studying HCC, summarising the currently available results. 
Keywords Choline - PET - FCH - Liver tumour . Hepatocellular carcinoma - Focal nodular hyperplasia . Hepatoblastoma

\section{Introduction}

Hepatocellular carcinoma (HCC) is the fifth most common neoplasm in the world and the leading cause of death among cirrhotic patients. Any focal liver lesion in a patient with cirrhosis is suggestive of HCC. Alpha-fetoprotein assay is the most frequently used biochemical screening test, but its accuracy in detecting HCC remains poor. Early detection may allow curative treatment in $30-40 \%$ of patients and therefore better survival results [1]. The most widely used radiological modality for screening is ultrasonography, which has a sensitivity of around $60 \%$ (even though this is considerably lower for small nodules) $[2,3]$. High-resolution contrast-enhanced computed tomography (CT) and magnetic resonance imaging (MRI) offer higher sensitivity: around 70 and $80 \%$, respectively [2, 4]. However, an additional 30-50 \% of unknown intra-hepatic sites of HCC, mostly $<2 \mathrm{~cm}$ in size, are found only at pathology after transplantation $[2,5]$.

To optimise patient management, early diagnosis and accurate staging of HCC before therapeutic decision-making would be facilitated by accurate detection of HCC foci both in the liver and at the whole-body level. Positron emission tomography (PET), which allows biological and metabolic characterisation of lesions with spatial resolution compatible with the detection of lesions $<2 \mathrm{~cm}$ in size, may allow detection at both these levels. The precise localisation of PET foci is achieved by fusion with images from an anatomical imaging modality, most frequently CT (PET/ $\mathrm{CT}$ ) and, in some advanced centres, MRI (PET/MRI).

The most widely used radiopharmaceutical for PET imaging in oncology is ${ }^{18} \mathrm{~F}$-fluorodeoxyglucose (FDG), a glucose analogue labelled with ${ }^{18} \mathrm{~F}$. In contrast with its excellent sensitivity for detecting liver metastases from most cancers, FDG PET shows limited sensitivity (50-70\%) for detecting intra-hepatic HCC lesions [6-11]. However, its sensitivity for detecting extra-hepatic HCC metastases, except for sub-centimetre lung metastases, is good [10-12]. HCC metastases are more frequently found in patients with intra-hepatic tumour $>5 \mathrm{~cm}$ in size [13, 14]. Furthermore, a positive intra-hepatic FDG focus, despite showing good specificity for benign versus malignant liver lesions, is of no help in characterising a malignant lesion as HCC, cholangiocarcinoma (CAC), sarcoma or a secondary lesion; several malignancies may be present in the liver of some patients [15].

Ho et al. [16] were the first to report better sensitivity with a lipid tracer $\left({ }^{11} \mathrm{C}\right.$-acetate $)$ than with FDG in the detection of
HCC on PET. In their study, performed to characterise liver masses, the sensitivity of $\mathrm{HCC}$ detection by ${ }^{11} \mathrm{C}$-acetate was $87 \%$, whereas the sensitivity of HCC detection by FDG was only $47 \%$ in the subgroup of patients with fewer than four lesions. No lesion was negative for both tracers (100\% sensitivity using both tracers). Histopathological correlation suggested that well-differentiated HCC tumours are detected by ${ }^{11} \mathrm{C}$-acetate and poorly differentiated types by FDG. These results have since been confirmed by several teams, as has the ability of ${ }^{11} \mathrm{C}$-acetate PET to detect distant metastases from HCC [17-21]. To optimise the diagnostic performance, most authors recommend a dual-tracer PET approach with ${ }^{11} \mathrm{C}$-acetate and FDG PET scans (in that order), which can even be performed on the same day [17, $18,20,21]$. However, the sensitivity of this approach for detecting small lesions between 1 and $2 \mathrm{~cm}$ in size has been found to be suboptimal: $32 \%$ for ${ }^{11} \mathrm{C}$-acetate and $27 \%$ for FDG in the study by Park et al. [20].

An advantage of ${ }^{11} \mathrm{C}$, in comparison with ${ }^{18} \mathrm{~F}$, is that of lower radiation exposure of the patient, due to its shorter half-life: $20 \mathrm{~min}$ for ${ }^{11} \mathrm{C}$ vs. $110 \mathrm{~min}$ for ${ }^{18} \mathrm{~F}$. However, this shorter half-life makes for more difficult logistics: an onsite cyclotron is needed and the radiopharmaceutical can only be labelled on-site for a very limited number of patients at each run. Labelling with ${ }^{18} \mathrm{~F}$, on the other hand, has the advantage of allowing the radiopharmaceutical to be prepared industrially and delivered to several PET centres.

These difficulties prompted the testing of an ${ }^{18} \mathrm{~F}$-labelled analogue of acetate, ${ }^{18}$ F-fluoroacetate (FAC). However, its performance in animal models [22] and recently in humans has been disappointing: in five HCC patients, none of the ${ }^{11} \mathrm{C}$-acetate-avid HCC lesions showed increased FAC activity [23].

Choline is one of the components of phosphatidylcholine, an essential element of phospholipids in the cell membrane. Cancer cells may be characterised by their ability to actively incorporate choline, to facilitate rapid cancer cell duplication. Significantly high choline levels have been detected in HCC with proton magnetic resonance spectroscopy [24].

The aim of the article is to provide an overview of PET imaging using the lipid tracer choline and its fluorinated analogues for studying HCC. The results of relevant available studies are summarised in Table 1 .

\section{Choline PET for detecting and localising hepatocellular carcinoma}

Results in animal models

In a hepatitis viral infection-induced woodchuck model of HCC, Salem et al. [25] found that FDG detected 7/13 


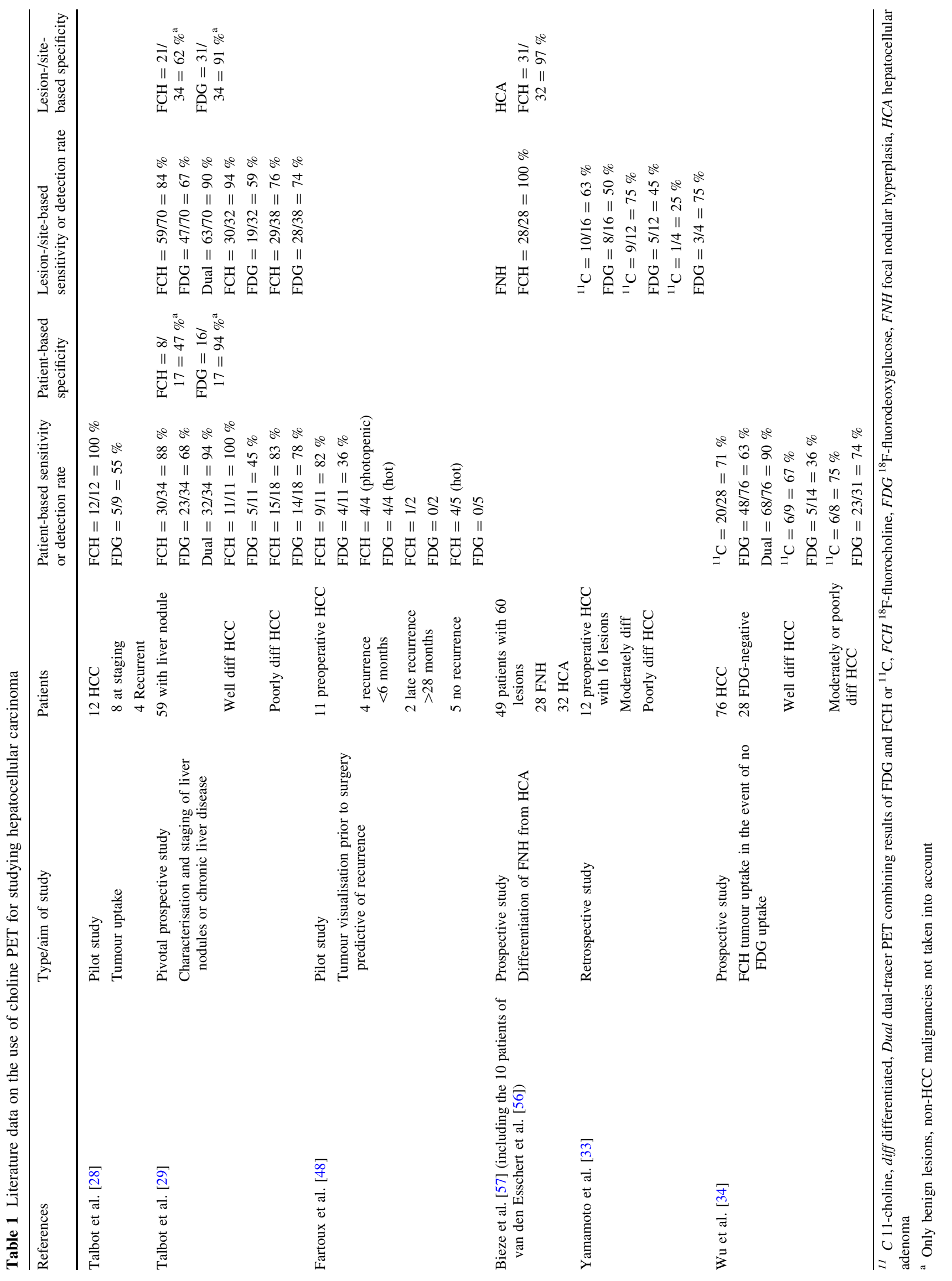


tumours; five of these HCCs were moderately or poorly differentiated. ${ }^{11} \mathrm{C}$-acetate instead detected 16/17 HCCs, while ${ }^{11} \mathrm{C}$-choline PET detected all HCCs. Kuang et al. [26], also in a woodchuck model, observed increased ${ }^{11} \mathrm{C}$ choline uptake in HCC, which was associated with choline transport and phosphorylation; the increased uptake of radiolabelled choline over time reflects increased phosphatidylcholine synthesis from cytidine $5^{\prime}$-diphosphocholine. By contrast, the surrounding hepatic tissues exhibited extensive oxidation of radiolabelled choline via the phosphatidylethanolamine methylation pathway, a major contributor to the observed physiological uptake.

Kolthammer et al. [27] compared uptake of ${ }^{11} \mathrm{C}$-choline and of ${ }^{18} \mathrm{~F}$-fluorethylcholine (FEC), a fluorinated analogue of choline, in a woodchuck HCC model. Foci of HCC with increased uptake ranged in size from 1.0 to $1.6 \mathrm{~cm}$, the mean tumour/non-tumour ratio (T/NTR) being 1.3 with FEC and 1.5 with ${ }^{11} \mathrm{C}$-choline at $50 \mathrm{~min}$ after injection. Tracer uptake patterns immediately after administration were similar, and both activities plateaued at $10 \mathrm{~min}$ after injection. Comparison of fasted and non-fasted states revealed no significant differences in uptake dynamics or final contrast.

The above preclinical studies yielded encouraging results regarding the capacity of choline and one of its fluorinated analogues to be rapidly taken up by HCC allowing PET visualisation of foci $<2 \mathrm{~cm}$ in size, in spite of significant accumulation in normal liver tissue. In one comparative study, ${ }^{11} \mathrm{C}$-choline detected $\mathrm{HCC}$ somewhat better than ${ }^{11} \mathrm{C}$-acetate did. The fact that tumour uptake plateaus as from $10 \mathrm{~min}$ until at least $50 \mathrm{~min}$ is an advantage: it makes whole-body imaging possible and it may reduce the waiting time between injection and image acquisition compared with what is possible with FDG PET.

\section{${ }^{18} \mathrm{~F}$-fluorocholine for detecting $\mathrm{HCC}$}

Talbot et al. proposed using ${ }^{18} \mathrm{~F}$-fluorocholine $(\mathrm{FCH})$, another fluorinated analogue of choline, for imaging HCC with PET/CT. The results of this proof-of-concept study published in 2006 were promising, with $\mathrm{FCH}$ found to show a better detection rate as compared with FDG. Of the nine patients with HCC who underwent FCH and FDG $\mathrm{PET} / \mathrm{CT}$, all were correctly diagnosed with $\mathrm{FCH}$; whereas, only five $(56 \%)$ were positive with FDG [28]. Normal hepatocytes accumulate FCH more intensely than FDG, resulting in a rather high liver background on FCH PET images. Thus, photopenic FCH areas, i.e. ones that are hypometabolic as compared with normal liver, can be visualised. When such photopenic areas were of tissue density on CT they corresponded to poorly differentiated aggressive malignant lesions.
The favourable result of this proof-of-concept study demonstrating uptake of FCH by HCC prompted the same team to conduct a phase III prospective study [29]. Its objective was to compare the diagnostic performance of FCH and FDG PET/CT in the detection of HCC in patients with liver nodules. The standard of truth was based on histology plus a 6-month follow-up, and was determined by an independent assessor blinded to results of the two PET/ CTs. It could be determined in 59 cases. Thirty-four patients were diagnosed with $\mathrm{HCC}$ or hepatocholangiocarcinoma (HCAC): 29 on the basis of histology and five using the Barcelona criteria. Twenty-five patients had other conditions which were histologically proven: other malignancies in eight subjects and benign hepatic diseases in 17 . Definite photopenic liver foci on FCH PET which corresponded to tissue density on CT were considered to indicate malignancy.

The patient-based sensitivity for detecting HCC or HCAC was $88 \%$ for FCH vs. $68 \%$ for FDG $(p=0.07)$.

Sensitivity was also evaluated on a per-site basis and 123 lesion sites were evaluated: 114 intra-hepatic and 9 extra-hepatic. For 70 HCC sites, the sensitivity was found to be $84 \%$ with $\mathrm{FCH}$, significantly higher than the $67 \%$ obtained with FDG $(p=0.01)$ (Figs. 1, 2). All FCH photopenic areas that could be histologically assessed corresponded to malignant lesions: HCC, but also CAC or metastases. Quantification of the SUVmax and calculation of the T/NTR had no added value over visual interpretation; this was at least partly due to the photopenic lesions on FCH PET/CT, which had a T/NTR definitely $<1$ but were actually malignant.

The superior sensitivity of FCH in well-differentiated HCC was statistically significant for both patient-based $(100 \%$ for $\mathrm{FCH}$ vs $45 \%$ for FDG, $p<0.003)$ and sitebased (94\% for FCH vs $59 \%$ for FDG, $p<0.001$ ) analyses. FDG had no added value over FCH in well-differentiated HCC since no false-negative lesion on FCH PET/ CT was true-positive on FDG PET/CT.

In less differentiated HCC or HCAC, the sensitivity of FCH and FDG PET/CT was not significantly different; e.g. site-based sensitivity was $76 \%$ for FCH vs $74 \%$ for FDG.

With regard to the effect of lesion size, of 12 sub-centimetre HCC lesions (minimum diameter $<1 \mathrm{~cm}$ ), 10 $(83 \%)$ were FCH-positive, and 8 (67\%) FDG-positive. These were better detection rates than those reported with ${ }^{11} \mathrm{C}$-acetate and FDG by Park et al. [20] for lesions of the same size (32 and $27 \%$, respectively). With regard to the two different lipid tracers ( $\mathrm{FCH}$ and ${ }^{11} \mathrm{C}$-acetate), the difference observed could be partly explained by the better spatial resolution of PET with ${ }^{18} \mathrm{~F}$ than with ${ }^{11} \mathrm{C}$ due to a shorter positron range [30], although a difference is also noted with the FDG. Alternatively, it could be due to a greater affinity of small HCC lesions for choline than for 


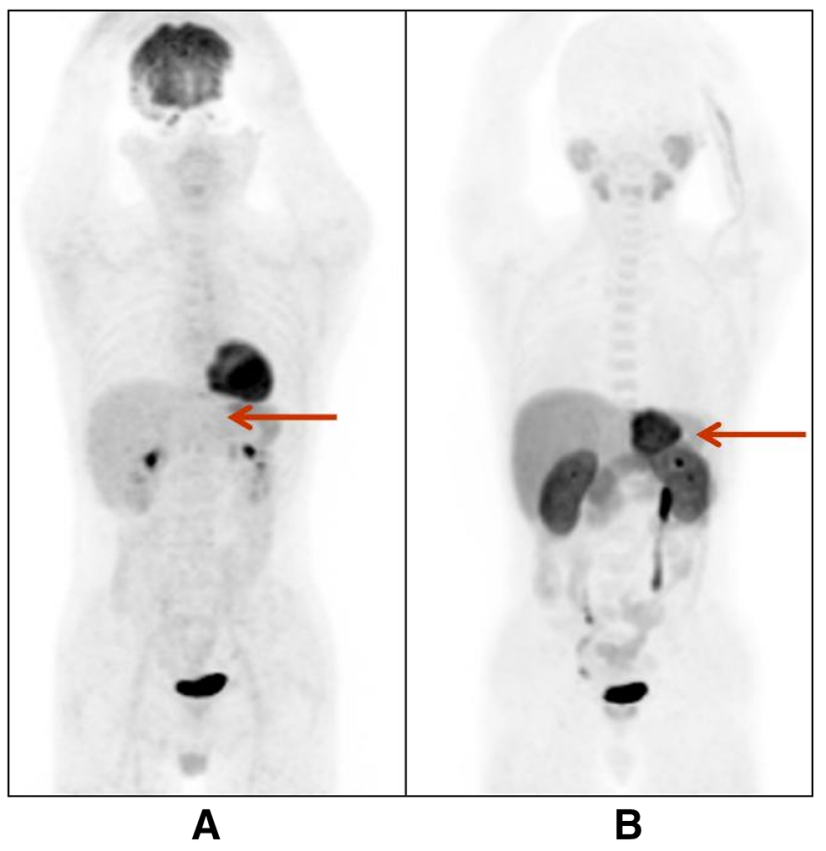

Fig. 1 Well-differentiated hepatocellular carcinoma: a typical case which appears FDG-negative (a) and FCH-positive (b) (color figure online)

acetate, as may be speculated from the results of the preclinical study of Salem et al. [25]?

With regard to results recorded in extra-hepatic lesions, in the pivotal study by Talbot et al. [29], only one site of lung metastasis from HCAC could be evaluated histologically, and this site took up both FCH and FDG. In the previous pilot study by the same team, $\mathrm{FCH}$ proved to be able to detect lung metastases and bone metastases with a more intense signal than that of FDG [28]. It must be taken into account that $\mathrm{FCH}$ is not specific for hepatic primaries; distant foci may correspond to another primary cancer [31], in particular prostate cancer [32].

In the study by Talbot et al. [29], the unexpected detection of distant extra-hepatic lesions resulted in an impact of FCH PET/CT on management in six patients, i.e. $7 \%$; this change was beneficial in five and unnecessary in one patient who underwent biopsy for a benign inflammatory lesion. Instead, had FCH been used only after FDG, it would have led to a beneficial change of management in only two patients (related to the capacity of FCH to detect abnormal prostate tissue). This could well be a large underestimation of the rate of change in management it might potentially induce, since the protocol of the study imposed that liver lesions should be characterised by biopsy or surgical resection and no change in the scheduled management of liver lesions occurred.

Ever since FCH obtained marketing authorisation in France in 2010, we have routinely performed dual-tracer
FCH and FDG PET/CT to characterise liver nodules and stage HCC. In particular, we have observed, in some large nodules, uptake exclusively of FCH by one part of the nodule and exclusively of FDG by the rest of the nodule. This pattern, illustrated in Fig. 2, is likely to correspond to different levels of HCC differentiation between different liver nodules and also within a given nodule; it has also been described with ${ }^{11} \mathrm{C}$-acetate and FDG dual-tracer PET [21].

${ }^{11} \mathrm{C}$-choline for detecting HCC

A pilot study by Yamamoto et al. [33] in 12 HCC patients found ${ }^{11} \mathrm{C}$-choline PET to have a better detection rate than FDG for moderately differentiated HCC lesions (75 vs. $25 \%$, respectively). Poorly differentiated HCC showed the opposite behaviour, with a detection rate of $42 \%$ for ${ }^{11} \mathrm{C}$ choline PET and $75 \%$ for FDG PET.

$\mathrm{Wu}$ et al. [34] evaluated the added value of ${ }^{11} \mathrm{C}$-choline in patients with HCC and negative FDG PET/CT. Positive FDG foci were found in 48 of 76 patients with HCC (61\%). In 28 HCC patients with negative FDG PET/CT, ${ }^{11} \mathrm{C}$-choline PET/CT was positive in $71 \%$. Compared with FDG PET, ${ }^{11} \mathrm{C}$-choline PET showed a trend towards improved detection of well-differentiated HCC (67 vs. $36 \%) .{ }^{11} \mathrm{C}$-choline and FDG PET/CT showed similar sensitivity for detecting moderately differentiated HCC (86 vs. $72 \%$ ). The diagnostic sensitivity was $63 \%$ with FDG PET/CT versus $90 \%$ with the dual-tracer modality $(p<0.001)$.

Summary of results on the use of lipid PET tracers for detecting $\mathrm{HCC}$

Even though the number of available studies remains limited and no comparative study has yet been performed, the choline PET tracers share a number of patterns with another tracer of lipid metabolism, ${ }^{11} \mathrm{C}$-acetate whose use for studying $\mathrm{HCC}$ is better documented. $\mathrm{FCH},{ }^{11} \mathrm{C}$-choline and ${ }^{11} \mathrm{C}$-acetate are able to detect well-differentiated intrahepatic HCC tissue better than FDG can [16, 20, 28, 29, 33, 34]. They are also effective in detecting poorly differentiated HCC, although no more so than FDG [20, 29, 34], the less differentiated types leading to visually FCH photopenic liver area. The ability of PET with FCH to detect extrahepatic metastases has been reported [29], but this ability is currently better documented with ${ }^{11} \mathrm{C}$-acetate $[17,18,20]$. Most authors concluded that dual-tracer PET/CTs, i.e. scanning with a lipid tracer and with FDG, is worthwhile and gives the best performance for HCC staging [17, 18, 20, 29, 35]. 
Fig. 2 Poorly differentiated hepatocellular carcinoma: partly FDG-positive (a) and partly FCH-positive (b), with FDGpositive areas appearing photopenic as compared to normal liver on FCH PET/CT (b) (color figure online)

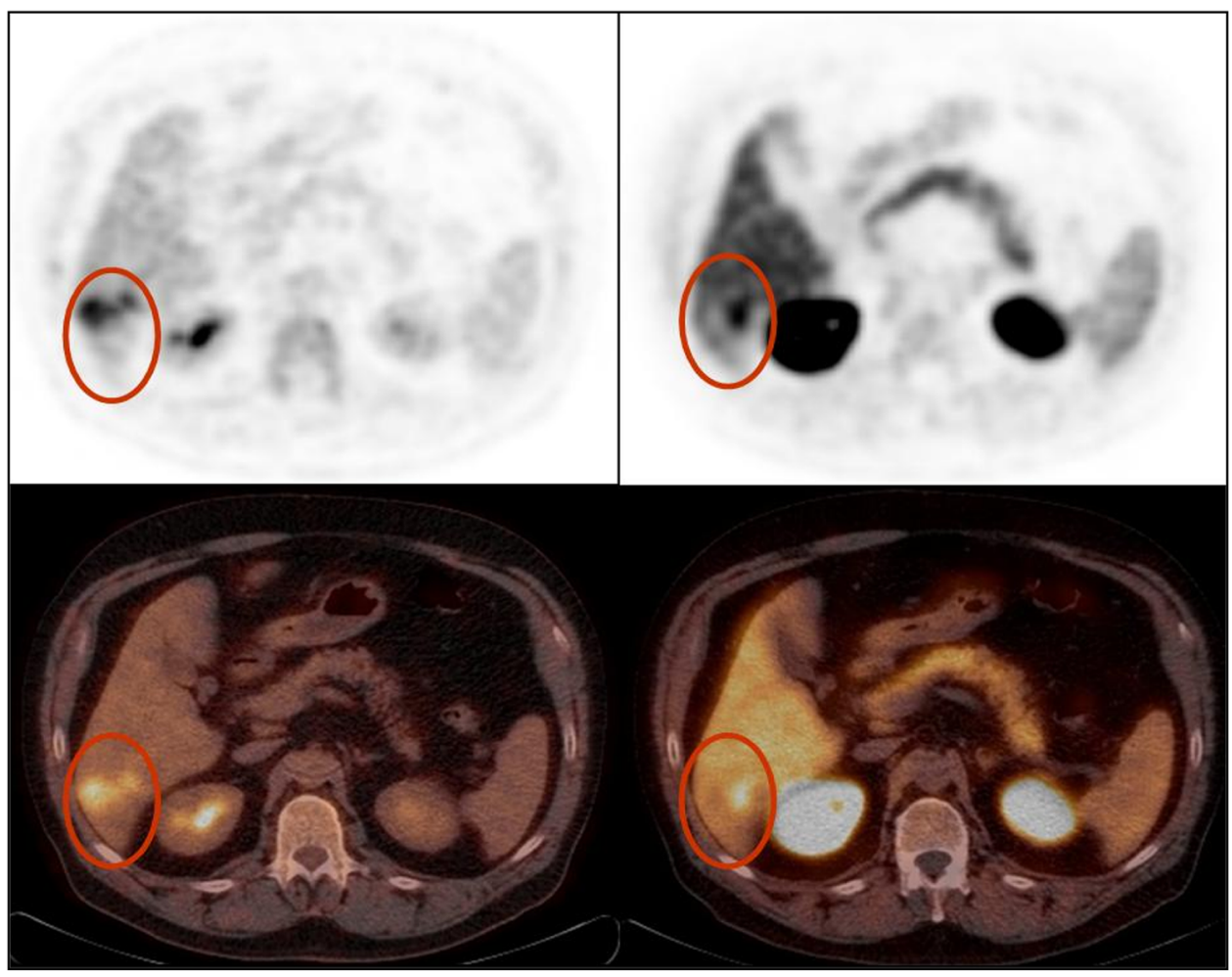

A
B

\section{Pre-treatment PET and HCC prognosis}

On the basis of the summarised results concerning the relationship between uptake of the PET radiotracers and HCC differentiation, a relationship with HCC prognosis can be anticipated. This may be of practical value, in particular for stratifying the risk of recurrence and helping to determine the best therapeutic option in a given patient.

The unfavourable prognostic value of high FDG uptake by HCC tumours prior to treatment is documented. The FDG T/NTR has been shown to be associated with poor differentiation and rapid doubling time of HCC [36]. Overall survival and disease-free survival at 2 years after resection have been found to be lower in patients whose HCC nodules strongly accumulated FDG on preoperative PET $($ T/NTR $\leq 2)$ [37, 38]. The predictive value of high FDG uptake on recurrence after resection has been confirmed by subsequent studies [39, 40]. The unfavourable prognostic value of HCC tumour visualisation on FDG PET in patients who are candidates for or scheduled for liver transplantation has also been reported by several teams [4144], whereas patients with non-FDG-avid HCC even at more advanced stage (beyond the Milan criteria) achieved excellent 5-year recurrence-free survival after liver transplantation [44]. FDG uptake has also shown predictive value for survival after non-surgical treatments [45-47].
Prognostic value of pre-surgical FCH

Fartoux et al. [48] performed a pilot study to compare the prognostic value, for disease-free survival, of preoperative dual-tracer imaging (FDG and FCH PET/CT) in 11 patients with resectable $\mathrm{HCC}$ who were then operated on. Only three tumour uptake patterns were observed in this limited series: FDG-positive and FCH photopenic tumour in four patients who were the only ones to relapse early, $<6$ months after resection; FDG-negative and FCH-positive in five patients of whom only one relapsed, after 40 months; no tumour visualisation either with FDG or with FCH in two patients, one of whom relapsed after 28 months. The worst PET pattern (FDG-positive FCH photopenic) was associated with the presence of microvascular invasion and satellite nodules in all cases. The association of FCH PET/CT with FDG PET/CT allowed better detection of early relapsers than did the use of a fixed FDG T/NTR cut-off value of 2 .

Potential prognostic value of pre-treatment PET with a lipid tracer in HCC patients

The body of evidence on this topic is, at present, very limited. Since well-differentiated HCC accumulates lipid tracers on PET, it can be speculated that lipid tracer uptake without any visible FDG uptake by HCC lesions would mean a good prognosis. Conversely, intense FDG uptake 
would indicate a bad prognosis and a high risk of recurrence. This was confirmed by the pilot study conducted by Fartoux et al. with FCH PET/CT [48] and in the larger series reported by Cheung et al. [19] who used ${ }^{11} \mathrm{C}$-acetate PET: the overall survival rates at three years were $82 \%$ for the 33 FDG-negative patients, $74 \%$ for the $56{ }^{11} \mathrm{C}$-acetateavid patients, $62 \%$ for the $25 \mathrm{FDG}$-avid patients, and $50 \%$ for the two ${ }^{11} \mathrm{C}$-acetate-negative patients.

Associating a pre-treatment FDG PET with a second PET performed with a lipid tracer, which shows better sensitivity than FDG for detecting HCC, can result in upstaging to multinodular or metastatic $\mathrm{HCC}$ and may impact on the therapeutic decision. But whether or not the prognostic evaluation of purely intra-hepatic HCC can also be refined by taking into account the uptake of the lipid tracer remains to be determined.

Choline PET for detecting and restaging persistent or recurrent $\mathrm{HCC}$

As HCC patients benefit from prolonged survival, screening for recurrence and then localisation and restaging of persistent or recurrent HCC is becoming increasingly important. Being a functional imaging modality, PET is usually better able than anatomical imaging to differentiate between viable cancer, residual non-viable tumour and scars after surgery or other invasive therapies. Detecting and restaging suspected persistence or recurrence of HCC following various types of local or regional treatment using FDG PET(/ CT) has been reported for almost two decades [11, 49-53].

By contrast, data with choline PET or other lipid tracers are currently limited. In 2007, Lendo et al. [54] reported restaging and extensive HCC recurrence with FCH PET. According to Talbot et al. [29], there was no difference in the detection of intra-hepatic HCC lesions between 46 patients without known $\mathrm{HCC}$ and 12 patients with a past history of HCC and suspected recurrence. In recurrent HCC, PET confirmed uptake by suggestive lesions in five patients with $\mathrm{FCH}$ and in three out of five with FDG.

\section{Positive choline PET in non-HCC liver tumours}

\section{FCH and non-HCC malignant tumours}

In the study by Talbot et al. [29], the only non-HCC liver malignancy reported to yield FCH-positive foci was CAC: 6/11 CAC liver sites in a single patient appeared as hot FCH foci, but 2 appeared as FCH photopenic areas in other two patients. Inversely 10/11 CAC sites were detected with FDG. Two isolated liver metastases of colorectal cancer appeared profoundly photopenic with $\mathrm{FCH}$, but clearly positive with FDG.
In children, hepatoblastoma is the most common primary liver malignancy, accounting for $1 \%$ of all paediatric malignancies. It was recently reported, in one patient, to take up FCH [55].

FCH uptake by benign liver tumours

In the study by Talbot et al. [29], aiming to detect $\mathrm{HCC}$ in liver nodules, FCH appeared overall less specific than FDG (62 vs. $91 \% p<0.01$ ), mostly due to uptake by focal nodular hyperplasia (FNH) (Fig. 3). Of eight patients with all or some liver nodules corresponding to $\mathrm{FNH}$, seven (88 \%) had positive FCH PET/CT. Of eight patients with pure adenoma, one had a positive FCH PET/CT (Figs. 4, 5). In one patient, cholangitis resulted in non-specific FCH uptake. None of the 31 benign liver lesions took up both FCH and FDG. No lesion of tissue density on CT, appearing photopenic on FCH PET, was benign.

This FCH uptake by FNH can be useful in the differential diagnosis with hepatocellular adenoma (HCA). The pilot study by van den Esschert et al. [56] included 10 patients with FNH and 11 with HCA. The mean T/NTR was $1.68 \pm 0.29( \pm \mathrm{SD})$ for $\mathrm{FNH}$ and $0.88 \pm 0.18$ for HCA $(p<0.001)$. A T/NTR cut-off value of between 1.12 and 1.22 differentiated patients with FNH from those with HCA, with $100 \%$ sensitivity and $100 \%$ specificity. A subsequent larger series reported by the same team [57] included a total of 49 consecutive patients with a suspicion of one or multiple HCAs or FNHs larger than $2 \mathrm{~cm}$; histopathology was obtained for 60 lesions. The mean T/NTR was $1.67 \pm 0.31$ for $28 \mathrm{FNH}$ lesions, which were all visible on FCH PET/CT, vs. $0.82 \pm 0.17$ for $32 \mathrm{HCA}$ lesions, of which only one was visible on FCH PET/CT. ROC curve analysis revealed an optimal T/NTR cut-off value of 1.13 , which reached $100 \%$ sensitivity and $97 \%$ specificity in differentiating FNH from HCA.

Summary of the results on the use of lipid PET tracers in non-HCC liver tumours

Metastases from non-HCC liver malignancies do not appear as hot foci on PET with lipid tracers [16, 29, 58], unlike CAC which can be visualised as a hot focus, in a proportion of cases that, however, cannot be evaluated from the small numbers of cases included in available series [16, 20, 29]. Lesions of tissue density on CT appearing photopenic on FCH PET correspond to malignancy [29]. With regard to screening for recurrent hepatoblastoma in children, only one case of FCH-positive recurrence has been published to date [54].

Considering the benign liver tumours, FNH lesions accumulate $\mathrm{FCH}$ [33] and, in more variable proportions, 
Fig. 3 Focal nodular hyperplasia $(\mathrm{FNH})$ is typically negative with FDG (a) and positive with $\mathrm{FCH}(\mathbf{b})$. This pattern may lead to falsepositive findings of FCH PET/ CT when hepatocellular carcinoma is suspected. However, FNH can be recognised on MRI. Conversely, this pattern may be useful to differentiate FNH from hepatocellular adenoma (color figure online)

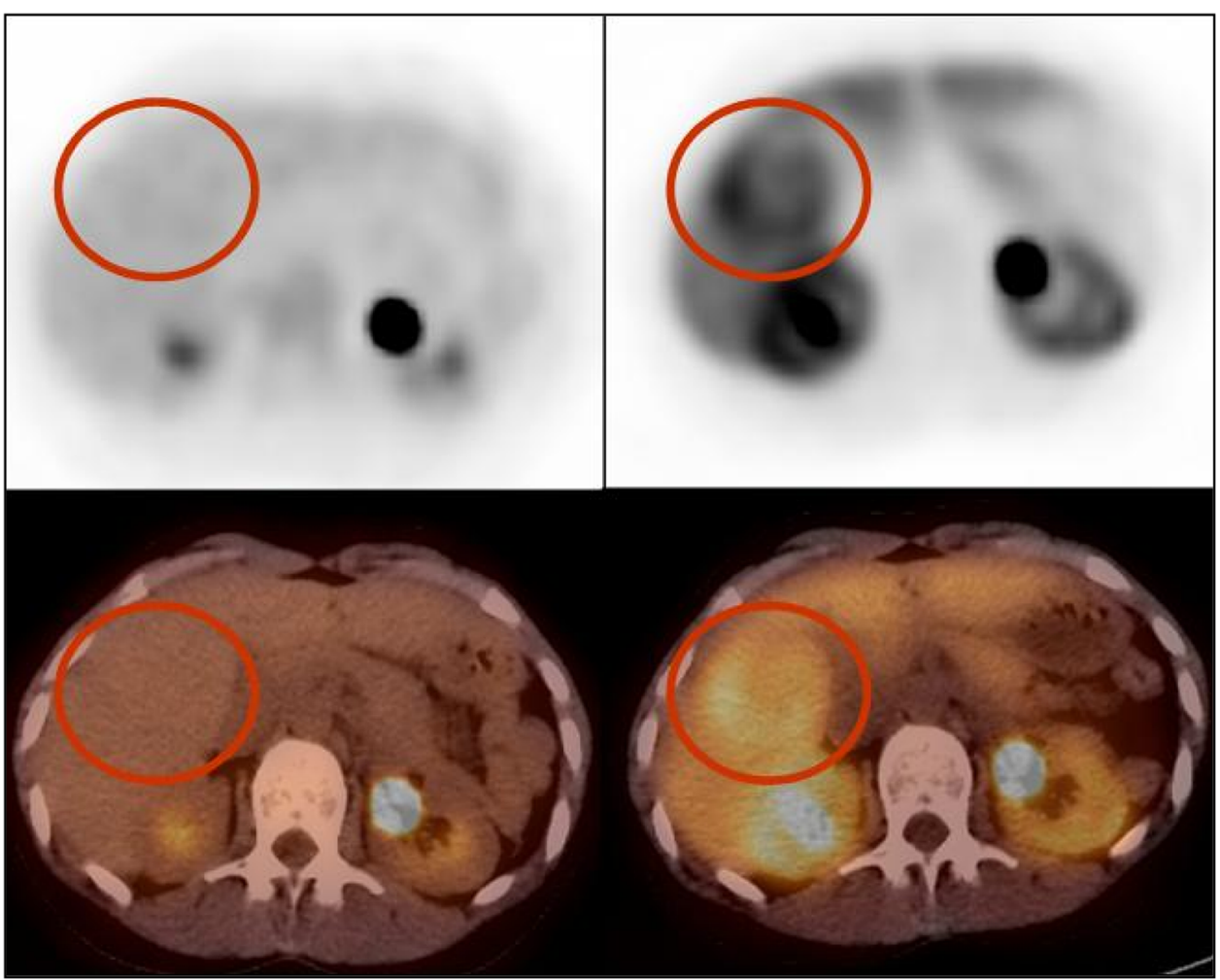

A

B

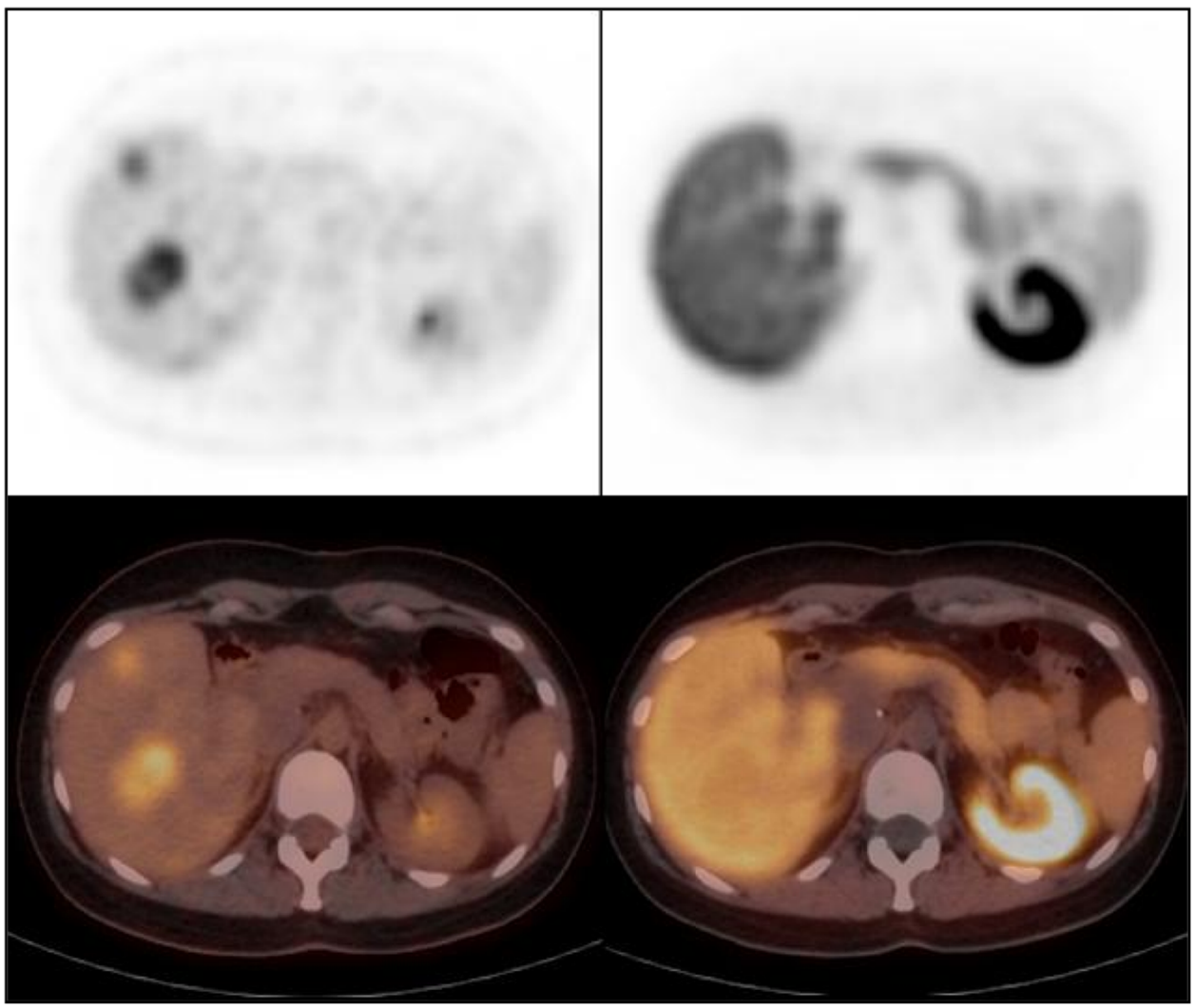

A
B 


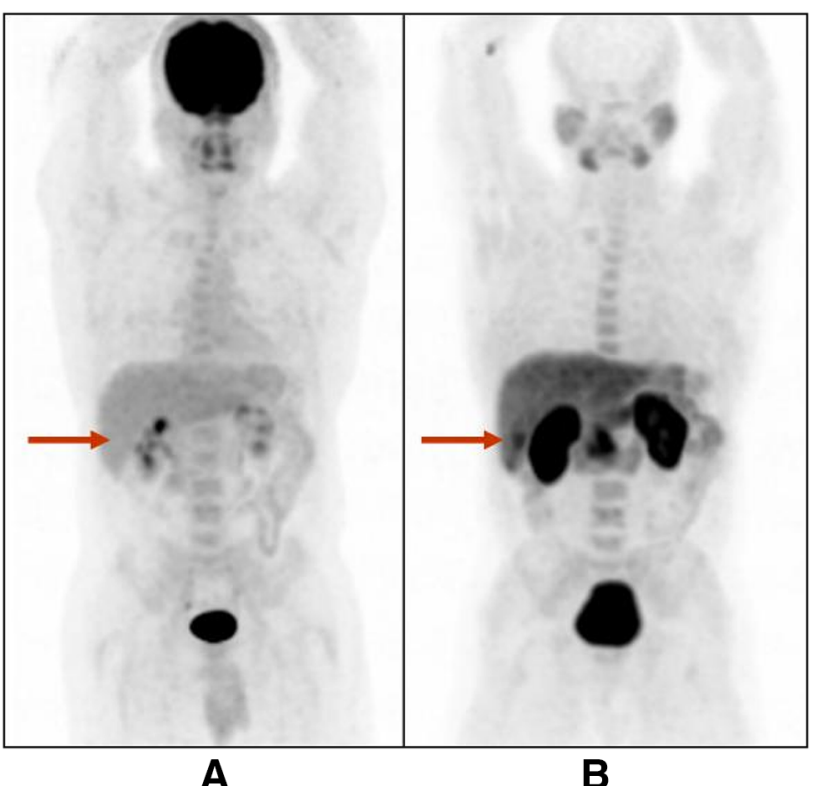

Fig. 5 Infrequently, liver adenoma can also be FDG-negative (a) and FCH-positive (b), as in this patient with a solitary adenoma (color figure online)

${ }^{11} \mathrm{C}$-acetate [16, 58, 59]. From a prognostic perspective, it is important to differentiate HCA, which can degenerate in up to $4 \%$ of lesions $[60,61]$, from FNH composed of normal hepatocytes occurring in a normal liver. Promising results for a role of $\mathrm{FCH}$ PET/CT in differentiating between those two benign lesion types were recently published [57].

Conversely, dual-tracer PET/CT cannot reliably characterise isolated liver nodules as malignant or benign [29, $56,57]$

\section{Conclusion}

FCH and ${ }^{11} \mathrm{C}$-choline compete with ${ }^{11} \mathrm{C}$-acetate as potential complements to FDG in the study of HCC. The added value of dual-tracer PET over FDG PET alone lies in the contribution it has been shown to make to the characterisation of liver nodules and the staging of HCC. FCH is the only one of these lipid tracers for PET to have been registered since 2010; it is also currently the only one that can be produced and delivered industrially. In the pivotal study of $\mathrm{FCH}$, sensitivity was not reduced in lesions of $0.7-2 \mathrm{~cm}$ in size as compared to larger lesions; this finding is important as it supports a role for $\mathrm{FCH}$ in the characterisation of small lesions missed by contrast-enhanced ultrasonography and MRI, but it is discordant with results reported with ${ }^{11} \mathrm{C}$-acetate. The effect of $\mathrm{HCC}$ lesion size in detection with FCH PET/CT, contrast-enhanced ultrasonography and MRI needs further study.
Further studies with choline PET tracers are also warranted in relation to the prognostic value of pre-treatment PET, its diagnostic performance in detecting and restaging persistent or recurrent HCC and the differentiation between FNH and HCA.

Acknowledgments The authors acknowledge the motivated team at the Nuclear Medicine Centre, Hôpital Tenon, for performing FCH PET/CT. They are grateful to Prof. Françoise Montravers, Dr Khaldoun Kerrou and Dr Virginie Huchet, who reported a great number of FCH PET/CTs and attended multidisciplinary cancer meetings, and also to Valérie Nataf, radiopharmacist, for her involvement in the clinical trial as a result of which $\mathrm{FCH}$ has been registered for imaging the liver. They are indebted to the referring physicians, in particular Dr Laetitia Fartoux, and digestive surgeons, in particular Prof. S. Houry, for their confidence and their willingness to share with us news regarding the follow-up of their patients, with the patients' consent.

Ethical standard This article does not contain any studies with human or animal subjects performed by any of the authors.

Conflict of interest J.-N. Talbot, L. Michaud, J.-D. Grange, O. Rosmorduc, S. Balogova declare that they have no conflict of interest.

\section{References}

1. Bruix J, Sherman M, Practice Guidelines Committee, American Association for the Study of Liver Diseases (2005) Management of hepatocellular carcinoma. Hepatology 42:1208-1236

2. Bennett GL, Krinsky GA, Abitbol RJ, Kim SY, Theise ND, Teperman LW (2002) Sonographic detection of hepatocellular carcinoma and dysplastic nodules in cirrhosis: correlation of pretransplantation sonography and liver explant pathology in 200 patients. AJR 179:75-80

3. Yu NC, Chaudhari V, Raman SS, Lassman C, Tong MJ, Busuttil RW, Lu DS (2011) CT and MRI improve detection of hepatocellular carcinoma, compared with ultrasound alone, in patients with cirrhosis. Clin Gastroenterol Hepatol 9(2):161-167

4. Snowberger N, Chinnakotla S, Lepe RM, Peattie J, Goldstein R, Klintmalm GB, Davis GL (2007) Alpha fetoprotein, ultrasound, computerized tomography and magnetic resonance imaging for detection of hepatocellular carcinoma in patients with advanced cirrhosis. Aliment Pharmacol Ther 26:1187-1194

5. Mazzaferro V, Regalia E, Doci R, Andreola S, Pulvirenti A, Bozzetti F, Montalto F, Ammatuna M, Morabito A, Gennari L (1996) Liver transplantation for the treatment of small hepatocellular carcinomas in patients with cirrhosis. N Engl J Med 334:693-699

6. Enomoto K, Fukunaga T, Okazumi S, Asano T, Kikuchi T, Yamamoto H, Nagashima T, Isono K, Itoh H, Imazeki K (1991) Can fluorodeoxyglucose-positron emission tomography evaluate the functional differentiation of hepatocellular carcinoma? Kaku Igaku 28:1353-1356

7. Delbeke D, Martin WH, Sandler MP, Chapman WC, Wright JK Jr, Pinson CW (1998) Evaluation of benign vs malignant hepatic lesions with positron emission tomography. Arch Surg 133(5): 510-515

8. Trojan J, Schroeder O, Raedle J, Baum RP, Herrmann G, Jacobi V, Zeuzem S (1999) Fluorine-18 FDG positron emission tomography for imaging of hepatocellular carcinoma. Am J Gastroenterol 94:3314-3319 
9. Khan MA, Combs CS, Brunt EM, Lowe VJ, Wolverson MK, Solomon H, Collins BT, Di Bisceglie AM (2000) Positron emission tomography scanning in the evaluation of hepatocellular carcinoma. J Hepatol 32(5):792-797

10. Teefey SA, Hildeboldt CC, Dehdashti F, Siegel BA, Peters MG, Heiken JP, Brown JJ, McFarland EG, Middleton WD, Balfe DM, Ritter JH (2003) Detection of primary hepatic malignancy in liver transplant candidates: prospective comparison of CT, MR imaging, US, and PET. Radiology 226(2):533-542

11. Wudel LJ Jr, Delbeke D, Morris D, Rice M, Washington MK, Shyr Y, Pinson CW, Chapman WC (2003) The role of [18F] fluorodeoxyglucose positron emission tomography imaging in the evaluation of hepatocellular carcinoma. Am Surg 69(2):117-124

12. Sugiyama M, Sakahara H, Torizuka T, Kanno T, Nakamura F, Futatsubashi M, Nakamura S (2004) ${ }^{18}$ F-FDG PET in the detection of extrahepatic metastases from hepatocellular carcinoma. J Gastroenterol 39(10):961-968

13. Yoon KT, Kim JK, do Kim Y, Ahn SH, Lee JD, Yun M, Rha SY, Chon CY, Han KH (2007) Role of ${ }^{18}$ F-fluorodeoxyglucose positron emission tomography in detecting extrahepatic metastasis in pretreatment staging of hepatocellular carcinoma. Oncology 72(suppl 1):104-110

14. Lee JE, Jang JY, Jeong SW, Lee SH, Kim SG, Cha SW, Kim YS, Cho YD, Kim HS, Kim BS, Jin SY, Choi DL (2012) Diagnostic value for extrahepatic metastases of hepatocellular carcinoma in positron emission tomography/computed tomography scan. World J Gastroenterol 18(23):2979-2987

15. Boursier J, Aubé C, Pilette C, Lassale V, Kerkeni N, Varache N (2006) Coexistence d'un carcinome hépato-cellulaire et d'une métastase hépatique. Intérêt de la tomodensitométrie par émission de positrons dans les tumeurs du foie. Radiology 87:1708-1710

16. Ho CL, Yu SC, Yeung DW (2003) ${ }^{11} \mathrm{C}$-acetate PET imaging in hepatocellular carcinoma and other liver masses. J Nucl Med 44(2):213-221

17. Ho CL, Chen S, Yeung DW, Cheng TK (2007) Dual-tracer PET/ CT imaging in evaluation of metastatic hepatocellular carcinoma. J Nucl Med 48(6):902-909

18. Ho CL, Chen S, Cheng TK, Leung YL (2011) PET/CT characteristics of isolated bone metastases in hepatocellular carcinoma. Radiology 258(2):515-523

19. Cheung TT, Chan SC, Ho CL, Chok KS, Chan AC, Sharr WW, Ng KK, Poon RT, Lo CM, Fan ST (2011) Can positron emission tomography with the dual tracers $\left[{ }^{11} \mathrm{C}\right]$ acetate and $\left[{ }^{18} \mathrm{~F}\right]$ fluorodeoxyglucose predict microvascular invasion in hepatocellular carcinoma? Liver Transpl 17(10):1218-1225

20. Park JW, Kim JH, Kim SK, Kang KW, Park KW, Choi JI, Lee WJ, Kim CM, Nam BH (2008) A prospective evaluation of ${ }^{18}$ F-FDG and ${ }^{11} \mathrm{C}$-acetate PET/CT for detection of primary and metastatic hepatocellular carcinoma. J Nucl Med 49(12):1912-1921

21. Larsson $P$, Arvidsson $D, B$ jörnstedt $M$, Isaksson $B$, Jersenius $U$, Motarjemi H, Jacobsson $\mathrm{H}$ (2012) Adding ${ }^{11} \mathrm{C}$-acetate to ${ }^{18} \mathrm{~F}$ FDG at PET examination has an incremental value in the diagnosis of hepatocellular carcinoma. Mol Imaging Radionucl Ther 21(1):6-12

22. Lindhe $\mathrm{O}$, Sun A, Ulin J, Rahman O, Långström B, Sörensen J (2009) $\left[{ }^{18} \mathrm{~F}\right]$ fluoroacetate is not a functional analogue of $\left[{ }^{11} \mathrm{C}\right]$ acetate in normal physiology. Eur $\mathrm{J}$ Nucl Med Mol Imaging 36(9):1453-1459

23. Ho CL, Cheung MK, Chen S, Cheung TT, Leung YL, Cheng KC, Yeung WD (2012) $\left[{ }^{18} \mathrm{~F}\right]$ fluoroacetate positron emission tomography for hepatocellular carcinoma and metastases: an alternative tracer for $\left[{ }^{11} \mathrm{C}\right]$ acetate? Mol Imaging 11(3):229-239

24. Li CW, Kuo YC, Chen CY, Kuo YT, Chiu YY, She FO, Liu GC (2005) Quantification of choline compounds in human hepatic tumors by proton MR spectroscopy at $3 \mathrm{~T}$. Magn Reson Med 53(4):770-776
25. Salem N, Kuang Y, Wang F, Maclennan GT, Lee Z (2009) PET imaging of hepatocellular carcinoma with 2-deoxy- $2\left[{ }^{18} \mathrm{~F}\right]$ fluoroD-glucose, 6-deoxy-6 $\left.6{ }^{18} \mathrm{~F}\right]$ fluoro-D-glucose, $\left[{ }^{1-11} \mathrm{C}\right]$-acetate and [N-methyl- ${ }^{11} \mathrm{C}$ ]-choline. Q J Nucl Med Mol Imaging 53(2):144-156

26. Kuang Y, Salem N, Tian H, Kolthammer JA, Corn DJ, Wu C, Wang F, Wang Y, Lee Z (2011) Imaging lipid synthesis in hepatocellular carcinoma with [methyl-11c] choline: correlation with in vivo metabolic studies. J Nucl Med 52(1):98-106

27. Kolthammer JA, Corn DJ, Tenley N, Wu C, Tian H, Wang Y, Lee Z (2011) PET imaging of hepatocellular carcinoma with ${ }^{18} \mathrm{~F}$ fluoroethylcholine and ${ }^{11} \mathrm{C}$-choline. Eur J Nucl Med Mol Imaging 38(7):1248-1256

28. Talbot JN, Gutman F, Fartoux L, Grange JD, Ganne N, Kerrou K, Grahek D, Montravers F, Poupon R, Rosmorduc O (2006) PET/ $\mathrm{CT}$ in patients with hepatocellular carcinoma using $\left[{ }^{18} \mathrm{~F}\right]$ fluorocholine: preliminary comparison with $\left[{ }^{18} \mathrm{~F}\right]$ FDG PET/CT. Eur J Nucl Med Mol Imaging 33(11):1285-1289

29. Talbot JN, Fartoux L, Balogova S, Nataf V, Kerrou K, Gutman F, Huchet V, Ancel D, Grange JD, Rosmorduc O (2010) Detection of hepatocellular carcinoma with PET/CT: a prospective comparison of ${ }^{18} \mathrm{~F}$-fluorocholine and ${ }^{18} \mathrm{~F}$-FDG in patients with cirrhosis or chronic liver disease. J Nucl Med 51(11):1699-1706

30. Peng H, Levin CS (2012) Study of PET intrinsic spatial resolution and contrast recovery improvement for PET/MRI systems. Phys Med Biol 57(9):N101-N115

31. Treglia G, Giovannini E, Di Franco D, Calcagni ML, Rufini V, Picchio M, Giordano A (2012) The role of positron emission tomography using carbon- 11 and fluorine- 18 choline in tumors other than prostate cancer: a systematic review. Ann Nucl Med 26(6):451-461

32. Balogova S, Bumsel F, Kerrou K, Huchet V, Nataf V, Mal F, Gutman F, Montravers F, Talbot JN (2010) La fluorocholine $\left({ }^{18} \mathrm{~F}\right)$ a une utilité clinique dans le cancer de la prostate et le carcinome hépatocellulaire...parfois chez le même malade. Méd Nucl 34(7):378-382

33. Yamamoto Y, Nishiyama Y, Kameyama R, Okano K, Kashiwagi H, Deguchi A, Kaji M, Ohkawa M (2008) Detection of hepatocellular carcinoma using ${ }^{11} \mathrm{C}$-choline PET: comparison with ${ }^{18} \mathrm{~F}$ FDG PET. J Nucl Med 49(8):1245-1248

34. Wu HB, Wang QS, Li BY, Li HS, Zhou WL, Wang QY $(2011){ }^{18} \mathrm{~F}$ FDG in conjunction with 11C-choline PET/CT in the diagnosis of hepatocellular carcinoma. Clin Nucl Med 36(12):1092-1097

35. Cheung TT, Ho CL, Lo CM, Chen S, Chan SC, Chok KS, Fung JY, Yan Chan AC, Sharr W, Yau T, Poon RT, Fan ST (2013) ${ }^{11} \mathrm{C}-$ acetate and ${ }^{18}$ F-FDG PET/CT for clinical staging and selection of patients with hepatocellular carcinoma for liver transplantation on the basis of Milan criteria: surgeon's perspective. J Nucl Med 54(2): 192-200

36. Shiomi S, Nishiguchi S, Ishizu H, Iwata Y, Sasaki N, Tamori A, Habu D, Takeda T, Kubo S, Ochi H (2001) Usefulness of positron emission tomography with fluorine-18-fluorodeoxyglucose for predicting outcome in patients with hepatocellular carcinoma. Am J Gastroenterol 96(6):1877-1880

37. Hatano E, Ikai I, Higashi T, Teramukai S, Torizuka T, Saga T, Fujii H, Shimahara Y (2006) Preoperative positron emission tomography with fluorine-18-fluorodeoxyglucose is predictive of prognosis in patients with hepatocellular carcinoma after resection. World J Surg 30(9):1736-1741

38. Seo S, Hatano E, Higashi T, Hara T, Tada M, Tamaki N, Iwaisako K, Ikai I, Uemoto S (2007) Fluorine-18 fluorodeoxyglucose positron emission tomography predicts tumor differentiation, $\mathrm{P}$-glycoprotein expression, and outcome after resection in hepatocellular carcinoma. Clin Cancer Res 13(2 Pt 1):427-433

39. Ahn SG, Kim SH, Jeon TJ, Cho HJ, Choi SB, Yun MJ, Lee JD, Kim KS (2011) The role of preoperative $\left[{ }^{18} \mathrm{~F}\right]$ fluorodeoxyglucose 
positron emission tomography in predicting early recurrence after curative resection of hepatocellular carcinomas. J Gastrointest Surg 15(11):2044-2052

40. Kitamura K, Hatano E, Higashi T, Seo S, Nakamoto Y, Yamanaka K, Iida T, Taura K, Yasuchika K, Uemoto S (2012) Preoperative FDG-PET predicts recurrence patterns in hepatocellular carcinoma. Ann Surg Oncol 19(1):156-162

41. Yang SH, Suh KS, Lee HW, Cho EH, Cho JY, Cho YB, Yi NJ, Lee KU (2006) The role of $\left({ }^{18}\right)$ F-FDG-PET imaging for the selection of liver transplantation candidates among hepatocellular carcinoma patients. Liver Transpl 12(11):1655-1660

42. Lee JW, Paeng JC, Kang KW, Kwon HW, Suh KS, Chung JK, Lee MC, Lee DS (2009) Prediction of tumor recurrence by ${ }^{18} \mathrm{~F}$ FDG PET in liver transplantation for hepatocellular carcinoma. J Nucl Med 50:682-687

43. Kornberg A, Freesmeyer M, Bärthel E, Jandt K, Katenkamp K, Steenbeck J, Sappler A, Habrecht O, Gottschild D, Settmacher U (2009) ${ }^{18}$ F-FDG-uptake of hepatocellular carcinoma on PET predicts microvascular tumor invasion in liver transplant patients. Am J Transplant 9(3):592-600

44. Kornberg A, Küpper B, Tannapfel A, Büchler P, Krause B, Witt U, Gottschild D, Friess H (2012) Patients with 18F-FDG non-avid advanced HCC on clinical staging may achieve recurrence-free long-term survival after liver transplantation. Liver Transpl 18(1):53-61

45. Kim BK, Kang WJ, Kim JK, Seong J, Park JY, do Kim Y, Ahn $\mathrm{SH}$, do Lee Y, Lee KH, Lee JD, Han KH, Kim BK, Kang WJ, Kim JK, Seong J, Park JY, do Kim Y, Ahn SH, do Lee Y, Lee KH, Lee JD, Han KH (2011) 18F-fluorodeoxyglucose uptake on positron emission tomography as a prognostic predictor in locally advanced hepatocellular carcinoma. Cancer 117(20):4779-4787

46. Song MJ, Bae SH, Yoo Ie R, Park CH, Jang JW, Chun HJ, Choi BG, Lee HG, Choi JY, Yoon SK (2012) Predictive value of ${ }^{18}$ F-fluorodeoxyglucose PET/CT for transarterial chemolipiodolization of hepatocellular carcinoma. World J Gastroenterol 18(25):3215-3222

47. Kucuk ON, Soydal C, Araz M, Bilgic S, Ibis E (2013) Prognostic importance of ${ }^{18}$ F-FDG uptake pattern of hepatocellular cancer patients who received SIRT. Clin Nucl Med 38(7):e283-e289

48. Fartoux L, Balogova S, Nataf V, Kerrou K, Huchet V, Rosmorduc O, Talbot JN (2012) A pilot comparison of ${ }^{18} \mathrm{~F}$-fluorodeoxyglucose and ${ }^{18} \mathrm{~F}$-fluorocholine PET/CT to predict early recurrence of unifocal hepatocellular carcinoma after surgical resection. Nucl Med Commun 33(7):757-765

49. Torizuka T, Tamaki N, Inokuma T, Magata Y, Yonekura Y, Tanaka A, Yamaoka Y, Yamamoto K, Konishi J (1994) Value of fluorine-18-FDG-PET to monitor hepatocellular carcinoma after interventional therapy. J Nucl Med 35(12):1965-1969

50. Anderson GS, Brinkmann F, Soulen MC, Alavi A, Zhuang H (2003) FDG positron emission tomography in the surveillance of hepatic tumors treated with radiofrequency ablation. Clin Nucl Med 28:192-197

51. Chen YK, Hsieh DS, Liao CS, Bai CH, Su CT, Shen YY, Hsieh JF, Liao AC, Kao CH (2005) Utility of FDG-PET for investigating unexplained serum AFP elevation in patients with suspected hepatocellular carcinoma recurrence. Anticancer Res 25(6C):4719-4725

52. Risse JH, Pauleit D, Bender H, Rabe C, Fischer HP, Biersack HJ, Bucerius J (2009) 18F-FDG-PET and histopathology in ${ }^{131} \mathrm{I}-$ lipiodol treatment for primary liver cancer. Cancer Biother Radiopharm 24:445-452

53. Sun L, Guan YS, Pan WM, Luo ZM, Wei JH, Zhao L, Wu H (2009) Metabolic restaging of hepatocellular carcinoma using whole-body F-FDG PET/CT. World J Hepatol 1(1):90-97

54. Lenzo NP, Anderson J, Campbell A, Morandeau L, De Grado TR (2007) Fluoromethylcholine PET in recurrent multifocal hepatoma. Australas Radiol 51(Suppl):B299-B302

55. Bieze M, van Gulik TM, Bennink RJ (2013) Hepatoblastoma evaluated by ${ }^{18} \mathrm{~F}$-fluoromethyl choline PET/CT. Clin Nucl Med 38(2):e80-e82

56. van den Esschert JW, Bieze M, Beuers UH, van Gulik TM, Bennink RJ (2011) Differentiation of hepatocellular adenoma and focal nodular hyperplasia using ${ }^{18} \mathrm{~F}$-fluorocholine PET/CT. Eur J Nucl Med Mol Imaging 38(3):436-440

57. Bieze M, Bennink RJ, El-Massoudi Y, Phoa SS, Verheij J, Beuers $\mathrm{U}$, van Gulik TM (2013) The use of ${ }^{18} \mathrm{~F}$-fluoromethylcholine $\mathrm{PET} / \mathrm{CT}$ in differentiating focal nodular hyperplasia from hepatocellular adenoma: a prospective study of diagnostic accuracy. Nucl Med Commun 34(2):146-154

58. Roivainen A, Naum A, Nuutinen $H$, Leino R, Nurmi $H$, Någren K, Parkkola R, Virtanen J, Kallajoki M, Kujari H, Ovaska J, Roberts P, Seppänen M (2013) Characterization of hepatic tumors using $\left[{ }^{11} \mathrm{C}\right]$ metomidate through positron emission tomography: comparison with $\left[{ }^{11} \mathrm{C}\right]$ acetate. EJNMMI Res 3(1):13

59. Magini G, Farsad M, Frigerio M, Serra C, Colecchia A, Jovine E, Vivarelli M, Feletti V, Golfieri R, Patti C, Fanti S, Franchi R, Lodi F, Boschi S, Bernardi M, Trevisani F (2009) C-11 acetate does not enhance usefulness of F-18 FDG PET/CT in differentiating between focal nodular hyperplasia and hepatic adenoma. Clin Nucl Med 34(10):659-665

60. Dokmak S, Paradis V, Vilgrain V, Sauvanet A, Farges O, Valla D, Bedossa P, Belghiti J (2009) A single-center surgical experience of 122 patients with single and multiple hepatocellular adenomas. Gastroenterology 137(5):1698-1705

61. Stoot JH, Coelen RJ, De Jong MC, Dejong CH (2010) Malignant transformation of hepatocellular adenomas into hepatocellular carcinomas: a systematic review including more than 1600 adenoma cases. HPB (Oxford) 12(8):509-522 